Conference abstract PMS04

\title{
Heterogeneous Hydrogenations in Continuous Flow
}

\author{
M. IRFAN, T. N. Glasnov, C. O. KAPPE \\ Christian Doppler Laboratory for Microwave Chemistry (CDLMC) and Institute of Chemistry, Karl-Franzens- \\ University Graz, Heinrichstrasse 28, A-8010 Graz, Austria \\ E-mail: muhammad.irfan@edu.uni-graz.at (M. Irfan)
}

Sci Pharm. 2010; 78: $631 \quad$ doi:10.3797/scipharm.cespt.8.PMS04

Catalytic heterogeneous hydrogenation processes arguably belong to the most valuable synthetic transformations known. Current batch reactor technology is not only time consuming and difficult to set up but also catalyst addition and filtration is hazardous. Because of the aromatic character of many substrates, hydrogenation often requires the use of significant hydrogen pressures in combination with elevated temperatures and extended reaction times.

In this context, continuous flow hydrogenation technology presents an attractive alternative to batch processing and the recent introduction of the $\mathrm{H}-\mathrm{Cube}{ }^{\mathrm{TM}}-\mathrm{a}$ continuous flow hydrogenation device incorporating in-situ hydrogen generation and pre-packed catalyst cartridges - has provided a safe and reliable method for performing hydrogenation reactions [1, 2].

In this poster we investigate the hydrogenations of olefins and heterocyclic aromatic rings. In general, the hydrogenations proceeded smoothly independent from the choice of the supported precious metal catalyst $(\mathrm{Pd} / \mathrm{C}, \mathrm{Pt} / \mathrm{C}$ or $\mathrm{Rh} / \mathrm{C})$. Using $30-80$ bar of hydrogen pressure at $60-80{ }^{\circ} \mathrm{C}$ full conversion was typically achieved in all cases at a flow rate of $0.5 \mathrm{~mL} \mathrm{~min}{ }^{-1}$ providing the corresponding piperidines in high yields. For disubstituted pyridines variations in stereoselectivity were observed depending on both the metal catalyst and on the temperature/pressure in the reaction. For ethyl nicotinate the selectivity between partial and full hydrogenation could be tuned depending on hydrogen pressure and the choice of the supported metal catalyst. Changing the hydrogen source from $\mathrm{H}_{2} \mathrm{O}$ to $\mathrm{D}_{2} \mathrm{O}$ allowed the preparation of deuterated derivatives [3].

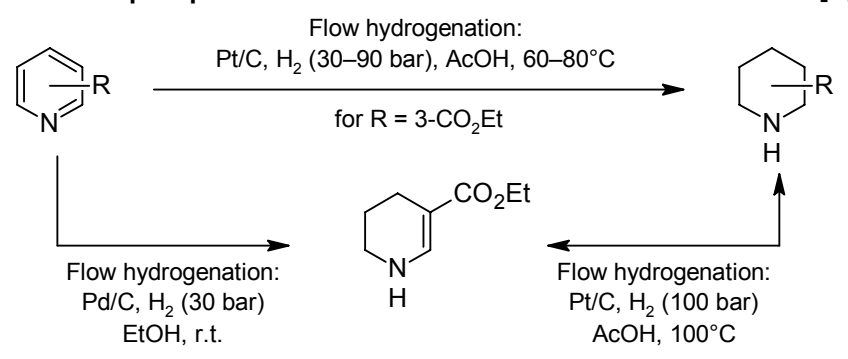

[1] Desai B, Kappe CO. Heterogeneous Hydrogenation Reactions Using a Continuous Flow High Pressure Device. J Comb Chem. 2005; 7: 641-643. doi:10.1021/cc050076x

[2] Desai B, Dallinger D, Kappe CO. Microwave-Assisted Solution Phase Synthesis of Dihydro- pyrimidine C5 Amides and Esters. Tetrahedron. 2006; 62: 4651-4664. doi:10.1016/j.tet.2005.12.061

[3] Irfan M, Petricci E, Glasnov TN, Taddei M, Kappe CO. Continuous Flow Hydrogenation of Functionalized Pyridines. Eur J Org Chem. 2009; 9: 1327-1334. doi:10.1002/ejoc.200801131 